\title{
ANALIZA RAZVOJA ODREĐENIH MOTORIČKIH SPOSOBNOSTI RAZLIČITO FIZIČKI AKTIVNE DECE PREDŠKOLSKOG UZRASTA
}

\author{
Apstrakt
}

Poslednjih godina brojna istraživanja motoričkog statusa dece predškolskog uzrasta pokazuju da su deca u ovom uzrastu manje fizički aktivna nego ranije. Po mišljenju istraživača, sve dominantniji sedentarni način života je vrlo verovatno uzrok brojnih zdravstvenih problema u detinjstvu i kasnijem životnom dobu. Istraživači predviđaju da će se i u budućnosti nastaviti trend smanjivanja fizičke aktivnosti, a samim tim i opadanje motoričkih sposobnosti uz sve veću prevalenciju prekomerne telesne mase i gojaznosti. Iako Kurikulum za predškolsko vaspitanje u predškolskom uzastu ne predviđa sistematičnog praćenja motoričkog razvoja dece, vrtići mogu imati važnu ulogu u preduzimanju koraka za prekidanje ovog trenda jer deca u njima provode značajan deo dana. Cilj predstavljene longitudinalne studije jeste analiza određenih motoričkih sposobnosti dece u periodu od jedne godine. Prigodni uzorak $(N=23)$ uzet je iz konkretne populacije dece uzrasta od četiri do pet godina. Merni instrument predstavljaju motorički testovi (zavisna varijabla). Nezavisnu varijablu predstavlja pohađanje dodatne sportske aktivnosti. Analizom varijanse (ANOVA) utvrđeno je da deca koja pohađaju dodatne sportske aktivnosti postižu bolje $(Z \geq .0414)$ rezultate na svim motoričkim testovima od dece koja ih ne pohađaju $(Z \leq-.0734)$. Uprkos činjenici da je razlika između dve grupe dece statistički značajna $(p<.05)$ samo na jednom od četiri testiranja, naše pretpostavke o boljim motoričkim sposobnostima dece koja pohađaju dodatne sportske aktivnosti su potvrđene.

Ključne reči: motorički razvoj, motorički testovi, deca predškolskog uzrasta, dodatna sportska aktivnost, longitudinalna studija

\footnotetext{
${ }^{1}$ ksenija.breg@gmail.com
} 


\section{Uvod}

Osnova ljudskog kretanja su urođeni motorički obrasci. Oni imaju genetsko uporište i predstavljaju osnovu za učenje i dalji razvoj. Reč je o onim velikim prekretnicama koje čine prirodan sled događaja u razvoju ljudskog kretanja. Karakteristični su za osobu i predstavljaju jednostavne, prirodne i namerne pokrete. To su podizanje glave, nespretno pomeranje, puzanje, hodanje, trčanje, bacanje, udarac, skok... (Škof, 2016). Prirodni načini kretanja su elementarna kretanja koja je čovek razvio u filogenezi, a na osnovu njih formirani su zahtevniji složeni oblici (Pistotnik, 2011). Prirodni načini kretanja su i osnova kretanja i važni su za život. Osobu prate od rođenja do smrti i omogućuju mu aktivan i kvalitetan život (Pišot \& Jelovčan, 2006). Pistotnik, Pinter \& Dolenec (2002) dele prirodne načine kretanja (abeceda kretanja čoveka) na pedipulacije ili lokomocije (gmizanje, puzanje, hodanje, trčanje, padanje, penjanje), manipulacije (bacanje i hvatanje predmeta, udarci i blokade udaraca, držanje) i složena kretanja (guranje, vučenje, dizanje, nošenje). Autori tvrde da upotreba prirodnih načina kretanja omogućuje razvoj većine motoričkih sposobnosti.

Svoj redosled imaju i faze motoričkog razvoja, koje se odvijaju po unapred određenom razvojnom nizu. On zavisi od zrelosti nervnog sistema, kostiju i mišića, od promena odnosa u telu i rada na usklađivanju funkcionisanja raznih grupa mišića. Redosled pojavljivanja razvojnih faza je načelno isti, ali se usled individualnih razlika među decom mogu pojaviti u različitim uzrastima (Škof, 2016).

Glavni procesi razvoja deteta su rast, sazrevanje i razvoj. Kako dete raste, postaje više i teže, a njegovi organi rastu. Proces sazrevanja je teže definisati. Cilj ovog procesa je zrelost. Sazrevanje nervnog i endokrinog sistema je glavni faktor seksualnog, skeletnog i somatskog sazrevanja. Tajming i tempo sazrevanja variraju od osobe do osobe. Razlikuju se kod devojčica i dečaka. Rast i sazrevanje se koriste zajedno sa terminom razvoja. Dete se razvija na kognitivnom, emocionalnom, socijalnom, moralnom i motoričkom području (Malina, Bouchard \& Bar-Or, 2004). Motorički razvoj je rezultat sazrevanja i učenja deteta. Dete može da zaostane u motoričkom razvoju ako nema mogućnosti za izvođenje motoričkih aktivnosti (Videmšek \& Visinski, 2001). Rajtmajer (1997) tvrdi da su individualne razlike u rezultatima dece jednakog biološkog uzrasta razvojna zakonitost, a ne izuzetak. Škof (2016) dodaje da se zbog individualnih razlika razvojne faze pojavljuju u različitim uzrastima i to treba uzeti u obzir u analizi faza motoričkog razvoja. Zurc (2011) smatra da nedostatak fizičke aktivnosti ili pogrešno, preterano ponavljanje određenih pokreta dovodi do nepravilnog fizičkog razvoja, a pritom usporava motorički, intelektualni, socijalni i emocionalni razvoj deteta.

Kretanje ima izuzetno važnu ulogu u razvoju osobe jer je kretanje, pored kiseonika, vode, energije (hrane), odmora i sl., jedna od temeljnih fizioloških potreba čoveka, kojima se održava u životu (Marinšek \& Rajtmajer, 2017). Videmšek i Visinski (2001) tvrde da se prirodna potreba deteta za kretanjem mora neprestano posmatrati i jačati.

Motorički razvoj je proces u kome dete razvija motoričke obrasce, stiče motoričke spretnosti i razvija motoričke sposobnosti. Motorički obrasci su urođene moto- 
ričke strukture: gmizanje, puzanje, hodanje, trčanje, itd. Motoričke spretnosti (engl. skills) ili veštine ili znanja objedinjuju nekoliko motoričkih obrazaca, a mogu biti proste ili složene, kao što je npr. dodavanje lopte tokom trčanja. Motoričke sposobnosti (engl. abilities) čoveku omogućavaju izvođenje motoričkih obrazaca ili motoričkih spretnosti, a istovremeno su osnova kretanja, npr. snaga, brzina, ravnoteža, koordinacija, izdržljivost (Mayer, 2005, sažetak po Škof, 2016).

Razvoj motoričkih sposobnosti tokom dužeg vremenskog perioda odvija se kontinuirano. Tipični su i povremeni periodi stagnacije, kao i opadanja sposobnosti. Neke motoričke sposobnosti dostižu najviši nivo ranije, a neke kasnije. Za razvoj nekih motoričkih sposobnosti u ranom detinjstvu tipično je da je, na primer, razvoj brzine i koordinacije vrlo intenzivan, a razvoj drugih, na primer, ravnoteže, snage, fleksibilnosti i izdržljivosti, nešto sporiji (Malina \& dr, 2004, sažetak po Pišot \& Planinšec, 2005; Videmšek \& Pišot, 2007). Motoričke sposobnosti određuju motoričko stanje čoveka. Pomoću njih možemo nešto uraditi, obaviti neki fizički zadatak. Procenat predispozicija u motoričkim sposobnostima je različit i nije precizno određen. U nekima je viši (npr. brzina), u nekima niži (npr. statična snaga i fleksibilnost). Motoričke sposobnosti se donekle i stiču vežbanjem i načinom života. To dovodi do različitog nivoa njihovog razvoja kod osoba (Videmšek \& Pišot, 2007). Uspeh izvođenja određenog fizičkog zadatka nikada ne zavisi samo od jedne motoričke sposobnosti. Uvek se aktiviraju različite motoričke sposobnosti, svaka sa svojim relativnim udelom (ibid).

Veze između različitih motoričkih sposobnosti i odgovarajući nivo njihovog razvoja su preduslov za racionalno i učinkovito fizičko kretanje. Motoričke sposobnosti koje obezbeđuju funkcionisanje regulacije kretanja (fleksibilnost, ravnoteža, pojavni oblici koordinacije kretanja) obezbeđuju uspostavljanje i održavanje ravnoteže, spretnost i zaštitu od povreda mišićnih vlakana, zglobova i drugih delova tela, kao i pravilno držanje tela. Bez adekvatnog razvoja motoričkih sposobnosti nije moguće sticati sportska znanja. Sportska znanja su, pak, preduslov za adekvatnu sportsku aktivnost koja omogućuje i veću potrošnju energije (Strel, et al., 2016).

Motoričke sposobnosti su merljive i na osnovu njih možemo uočiti razlike u uspehu izvođenja određenog motoričkog zadatka između dva subjekta u jednakim uslovima, znanju i motivaciji (Videmšek \& Pišot, 2007). Marinšek \& Rajtmajer (2017) navode, da motoričke sposobnosti merimo na osnovu učinkovitosti rešavanja odabranih motoričkih zadataka. Učinkovitost rešavanja zadataka otkriva nivo motoričkih sposobnosti pojedinca.

Volmut i Šimunič (2016) navode nedavno objavljene studije koje govore da deca predškolskog uzrasta u protekloj deceniji postaju sve manje fizički aktivna i ne ostvaruju najmanje 60 minuta fizičke/sportske aktivnosti srednjeg i visokog intenziteta dnevno.

Šimunič, et al. (2010) smatraju da su deca predškolskog uzrasta manje fizički aktivna nego ranije. Po mišljenju autora, sve dominantniji sedentarni način života je vrlo verovatno uzrok brojnih zdravstvenih problema u detinjstvu i kasnijim životnim periodima. Na osnovu brojnih istraživanja (Papalia, et al., 2003; Šimunič, 2008; Vi- 
demšek \& Pišot, 2007; Zajec, et al., 2010; Zurc, 2011), predviđaju da će se i u budućnosti nastaviti trend smanjivanja fizičke aktivnosti, a samim tim i smanjenje motoričkih sposobnosti uz sve veću prevalenciju prekomerne telesne mase i gojaznosti. Vrtići mogu imati važnu ulogu u preduzimanju koraka za prekidanje ovog trenda jer znamo da deca u njima provode značajan deo dana.

Tucker i Gilliland (2007) su utvrđivali uticaj godišnjih doba i vremena na fizičku aktivnost. Utvrdili su da fizička aktivnost varira u skladu sa godišnjim dobima, vremenom, lokalnim sezonskim temperaturama, padavinama i dužinom dana. U hladnijim i vrućim mesecima, fizička aktivnost opada. Deca predškolskog uzrasta su manje fizički aktivna u hladnim mesecima nego u toplijim mesecima. Zbog lošeg i ekstremnog vremena, fizička aktivnost opada.

Baranowski, Thompson, Durant, Baranowski i Puhl (1993) zaključuju da su deca stara tri i četiri godine stalno fizički aktivnija napolju nego u zatvorenom prostoru. Zato decu treba podsticati da se što duže igraju napolju, i to u svim godišnjim dobima.

Američko nacionalno udruženje za sport i fizičko vaspitanje (NASPE) (2006), koje navode Volmut i Šimunič (2016), izdalo je preporuke za fizičku/sportsku aktivnost dece predškolskog uzrasta. Za decu predškolskog uzrasta preporučuje se barem 120 minuta fizičke/sportske aktivnosti dnevno, od čega bi 60 minuta moralo biti posvećeno organizovanoj vežbi, a 60 minuta ili više neorganizovanoj vežbi. Deca od prve do pete godine starosti ne bi trebalo da sede zgrčeno duže od 60 minuta. Zurc (2011) tvrdi da pozitivan uticaj na razvoj deteta može imati samo ona fizička aktivnost koja je odgovarajuća po učestalosti, obliku i sadržaju. Autorka dodaje da bi prema preporuci Svetske zdravstvene organizacije (WHO, 2010) takva aktivnost trebalo da traje svakog dana, najmanje 60 minuta. Preporučuju i učešće u organizovanim fizičkim aktivnostima koje se odvijaju pod stručnim vođenjem. Bratina i dr. (2011) takođe daju savete kako da se organizuje svakodnevna vežba za decu, i smatraju da bi podsticanje fizičke aktivnosti na državnom nivou trebalo da bude agresivnije kako bi se ostvarile dobro zamišljene smernice i ciljevi predloženog nacionalnog programa sporta.

\section{Metoda}

Cilj longitudinalne studije je analiza određenih motoričkih sposobnosti dece u periodu od jedne godine na osnovu kauzalne neeksperimentalne metode. Cilj je bio da se utvrde razlike u motoričkom razvoju dece koja dodatnu sportsku aktivnost pohađaju jednu godinu $(6 ; 26,1 \%)$, dece koja dodatnu sportsku aktivnost pohađaju već dve godine $(6 ; 26,1 \%)$, i dece koja ne pohađaju dodatnu sportsku aktivnost $(11 ; 47,8 \%)$. Prigodni uzorak je uzet iz konkretne populacije dece predškolskog uzrasta koja su na početku studije bila stara četiri godine $+/-3$ meseca. Uzorak je činilo 23 dece, 11 $(47,8, \%)$ devojčica i $12(52,2 \%)$ dečaka. Podatki su prikupljeni kvantitativnom metodom. Tokom jedne godine izvedeno je četiri merenja motoričkih sposobnosti. Radi praćenja motoričkog razvoja, na svakom testiranju upotrebljeno je deset motoričkih 
testova (Fjørtoft i dr, 2011; Haga, 2009; Pistotnik, 2011; Rajtmajer, 1997), koji su detaljno opisani u istraživanju Breg (2018). Dobijeni podatki su kvantitativno obrađeni statističkim programom SPSS. Imajući u vidu želju za generalizacijom, upotrebljena je deskriptivnu statistiku, a zbog broja varijabli, analizu varijanse (ANOVA).

\section{Rezultati istraživanja}

U periodu od septembra 2016. do septembra 2017. izvedena su četiri testiranja u vrtiču Šentilj (test 1 septembar 2016, test 2 januar 2017, test 3 maj 2017. i test 4 septembar 2017). Deca su u tom periodu jednom nedeljno pohađala košarku kao dodatnu sportsku aktivnost. Kako bismo izračunali ukupne rezultate motoričkih sposobnosti, standardizovali smo rezultate $(Z)$ motoričkih testova. Na taj način smo mogli da prikažemo ukupni rezultat motoričkih testova koji su izraženi različitim mernim jedinicama. Deskriptivni obračun rezultata pojedinačnih merenja prikazan je na Grafikonu 1.

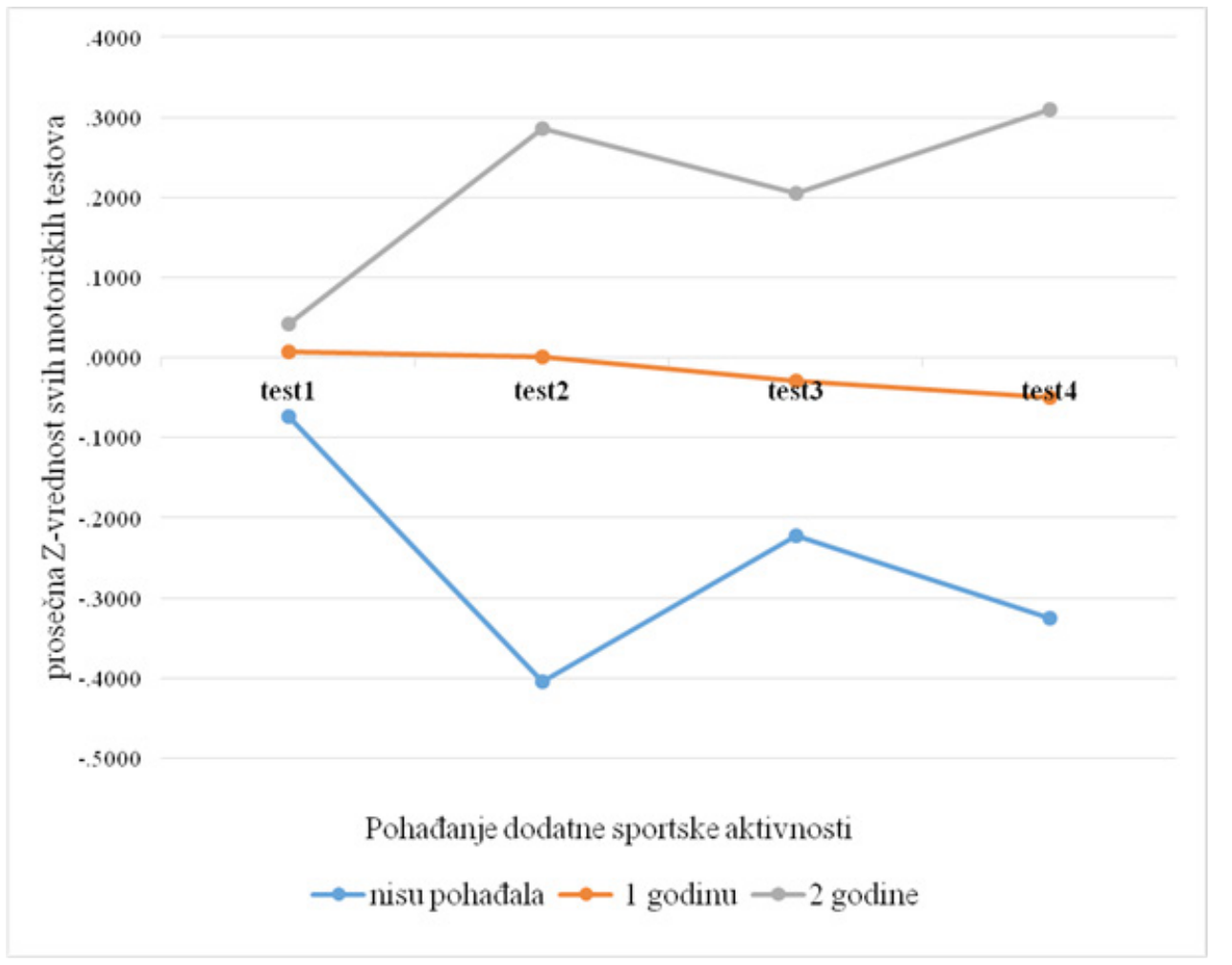

Grafikon 1: Ukupni rezultati motoričkih testova u zavisnosti od pohađanja dodatne sportske aktivnosti. 
Metodom analize varijanse (ANOVA) proverili smo da li postoji statistički značajna razlika $(\mathrm{p}<.05) \mathrm{u}$ rezultatima motoričkih testova dece koja su različito pohađala dodatnu sportsku aktivnost (Tabela 1).

Tabela 1

Statistički značajna razlika (p) u rezultatima motoričkih testova na pojedinačnim testiranjima u zavisnosti od pohađanja dodatne sportske aktivnosti

\begin{tabular}{lrrrr}
\hline & \multicolumn{3}{c}{ Pohađanje dodatne sportske aktivnosti } & \\
\cline { 2 - 4 } motorički test & nisu pohađala & 1 godinu & 2 godine & \multicolumn{1}{c}{$\mathrm{p}$} \\
\hline test1 $(9 / 2016)$ & -.0734 & .0070 & .0414 & .810 \\
test2 $(1 / 2017)$ & -.4038 & .0014 & .2862 & $.044^{*}$ \\
test3 $(5 / 2017)$ & -.2227 & -.0297 & .2058 & .372 \\
test4 $(9 / 2017)$ & -.3254 & -.0491 & .3096 & .121 \\
\hline
\end{tabular}

Napomena: $* p<.05$

Tabela 1 prikazuje zajedničke rezultate motoričkih sposobnosti $(Z)$ na pojedinačnim testiranjima u zavisnosti od pohađanja dodatne sportske aktivnosti. Deca koja su dve godine pohađala dodatnu sportsku aktivnost ostvarila su natprosečne rezultate na svim testiranjima $(Z>0)$. Deca koja su jednu godinu pohađala dodatnu sportsku aktivnost ostvarila su natprosečne rezultate samo na prva dva testiranja $(Z>0)$. Deca koja nisu pohađala dodatnu sportsku aktivnost ostvarila su ispotprosečne rezultate na svim testiranjima $(Z<0)$. Tabela 1 takođe pokazuje da su deca koja su dve godine pohađala sportsku aktivnost na svim rezultatima postigla najbolje rezultate $(Z \geq .0414)$, a deca koja nisu pohađala dodatnu sportsku aktivnost na svim testiranjima postigla su najlošije rezultate ( $\mathrm{Z} \geq-.0734)$. Rezultati analize varijanse (ANOVA) pokazuju da se $u$ rezultatima motoričkih testova samo na drugom testiranju pojavila statistički značajna razlika među decom koja su različito pohađala dodatnu sportsku aktivnost $(\mathrm{p}=.044)$.

\section{Diskusija (sa pedagoškim implikacijama)}

Zaključci predstavljenog istraživanja pokazuju da deca koja pohađaju dodatnu sportsku aktivnost postižu bolje rezultate na motoričkim testiranjima od dece koja je ne pohađaju. Takav rezultat smo očekivali jer se o toj vezi mnogo pisalo u stručnoj literaturi. Strel i dr. (2016) tvrde da samo odgovarajuće opterećenje tela garantuje pozitivne učinke motoričkih sposobnosti. Zhou i dr. (2014) takođe utvrđuju da prikladni programi dodatnih sportskih aktivnosti poboljšavaju motoričke sposobnosti kod dece predškolskog uzrasta. Zajec i dr. (2010) smatraju da na sistematičnost razvoja motoričkih sposobnosti i spretnosti značajno utiču i roditelji, sportski pedagozi i ostali profesionalni sportski radnici koji organizuju sportsku aktivnost za decu predškolskog uzrasta. 
Rezultati istraživanja takođe pokazuju da su deca koja nisu pohađala dodatnu sportsku aktivnost na motoričkim testovima postizala značajno lošije rezultate od dece koja su pohađala dodatnu sportsku aktivnost. Ovaj zaključak potvrđuju i Videmšek i dr. (2003; sažetak po Zdešar \& Porenta, 2016), koji tvrde da motorički razvoj deteta može usporiti nedostatak iskustva i premalo mogućnosti za učešće u fizičkim aktivnostima. Sa svim napisanim slaže se Pišot (1999, sažetak po Zurc, 2008), koji tvrdi da dolazi do sve većih razlika među decom koja vrlo rano usvajaju razna motorička znanja i decom koja nisu dobijala podsticaje ili su ih dobijala mnogo kasnije.

Motorički razvoj je proces u kome dete razvija motoričke obrasce, stiče motoričke spretnosti i razvija motoričke sposobnosti. Budući da su motoričke sposobnosti osnova za izvođenje motoričkih spretnosti, učenje i izvođenje novih, sve zahtevnijih motoričkih spretnosti u značajnoj meri je uslovljeno nivoom motoričkih sposobnosti. Pišot \& Planinšec (2005) smatraju da što je viši nivo motoričkih sposobnosti, uspešnije će biti učenje i izvođenje motoričkih spretnosti. Prenizak nivo motoričkih sposobnosti smanjuje mogućnost uspešnog učenja, dok visok nivo motoričkih sposobnosti omogućava usvajanje i izvođenje zahtevnijih motoričkih spretnosti.

\section{Zaključak}

Na osnovu rezultata longitudinalne studije možemo zaključiti da sopstvena aktivnost, interes dece i pozitivni podsticaji iz okruženja koji decu usmeravaju prema dodatnim sportskim aktivnostima utiču na poboljšavanje motoričkih sposobnosti dece, kao i da se smanjuju motoričke sposobnosti dece koja nisu fizički aktivna i nemaju podsticajno okruženje koje ih usmerava prema dodatnim sportskim aktivnostima.

Ubuduće u ovakve studije trebalo bi uključiti veći broj dece i veći broj motoričkih testova koji će šire i preciznije pojasniti motorički status dece. Roditeljima predlažemo da deca pohađaju dodatne sportske aktivnosti jer smo i sami dokazali da veća količina sportskih aktivnosti pozitivno utiče na razvoj motoričkih sposobnosti. Vaspitačima u vrtićima predlaže se da u svoj rad sa decom uključe merne postupke predstavljene u ovom istraživanju, pomoću kojih mogu objektivno i sa jednostavnim sportskim pomagalima i rekvizitima u daljem vremenskom periodu pratiti motorički razvoj dece. Na osnovu rezultata tako mogu pratiti napredak dece na motoričkom području i u skladu sa tim pripremiti program potrebnih sportskih aktivnosti za razvoj motoričkih sposobnosti dece predškolskog uzrasta, čime se sedentarni način života dece preusmerava u aktivan način života. 


\title{
Ksenija Breg
}

Vrtič Šentilj

Slovenija

\section{ANALYSIS OF THE DEVELOPMENT OF CERTAIN MOTOR ABILITIES OF VARIOUS PHYSICALLY ACTIVE PRESCHOOL CHILDREN}

\begin{abstract}
In recent years, numerous studies of the motor status of pre-school children have shown that children are less active in this age period than they used to be in the past. According to the researchers, the increasingly dominant sedentary lifestyle triggers many health problems in childhood and later life periods. Researchers predict that the trend in decline in motor activity and consequently the decline in motor abilities, and at the same time, the increasing prevalence of overweight and obesity will continue in future. Pre-school education curriculum fails to provide systematic monitoring of the motor development of preschool children. In addition, kindergartens can play an important role as children spend a considerable part of the day in it. The purpose of the longitudinal study presented was to analyze some motor abilities of children over a period of one year. The convenience sample $(\mathrm{N}=23)$ is made of specific population of four to five year olds. The measuring instrument represents motor tests (dependent variable). An independent variable represents the attendance of additional sports activities. Using the analysis of variance (ANOVA), it was found that children who attend additional sports activities achieve better results in all motor tests $(Z \geq .0414)$ in comparison with the children who fail to attend these activities $(Z \leq-.0734)$. Despite the fact that the difference between groups of children is statistically significant $(p<.05)$ only in one of four tests, our assumptions about better motor abilities of children who attend additional sports activities are confirmed.
\end{abstract}

Keywords: motor development, motor tests, pre-school children, additional sports activity, longitudinal study

\section{Literatura}

Baranowski, T., Thompson, W. O., Durant, R. H., Baranowski, J., \& Puhl, J. (1993). Observations on physical activity in physical locations: Ager gender, ethnicity, and month effects. Research quarterly for exercise and sport, 64(2), 127-133.

Bratina, N., Hadžić, V., Batellino, T., Pistotnik, B., Pori, M., Šajber, D., \& Dervišević, E. (2011). Slovenske smernice za telesno udejstvovanje otrok in mladostnikov v starostni skupini od 2 do 18 let. Zdravstveni vestnik, 80(12), 885-896. 
Breg, K. (2018). Analiza razvoja nekaterih gibalnih sposobnosti in telesnih razsežnosti različno gibalno dejavnih in prehranjenih otrok v starosti od četrtega do šestega leta (diplomski rad). Maribor: Univerza v Mariboru, Pedagoška fakulteta.

Fjørtoft, I., Pedersen, A. V., Sigmundsson, H., \& Vereijken, B. (2011). Measuring physical fitness in children who are 5 to 12 years old with a test battery that is functional and easy to administer. Physical therapy, 91(7), 1087-1095.

Haga, M. (2009). Physical Fitness in Children With High Motor Competence Is Different From That in Children With Low Motor Competence. Physical Therapy, 89(10), 1089-1097.

Malina, R. M., Bouchard, C., \& Bar-Or, O. (2004). Growth, maturation and physical activity. United States of America: Human Kinetics.

Marinšek, M., \& Rajtmajer, D. (2017). Šport v funkciji doživljajske vzgoje. Ljubljana: Amalietti \& Amalietti.

Papalia, D. E., Wendkos Olds, S., \& Duskin Feldman, R. (2003). Otrokov svet. Ljubljana: Educy.

Pistotnik, B. (2011). Osnove gibanja v športu - osnove gibalne izobrazbe. Univerza v Ljubljani, Fakulteta za šport. Ljubljana.

Pistotnik, B., Pinter, S., \& Dolenec, M. (2002). Gibalna abeceda. Ljubljana: Fakulteta za šport, Inštitut za šport.

Pišot, R., \& Planinšec, J. (2005). Struktura motorike v zgodnjem otroštvu. Koper: Univerza na Primorskem, Znanstveno - raziskovalno središče, Inštitut za kineziološke raziskave, Založba Annales.

Pišot, R., \& Jelovčan, G. (2006). Vsebina gibalne/športne vzgoje v predšolskem obdobju. Koper: Univerza na Primorskem, Znanstveno-raziskovalno središče.

Rajtmajer, A. (1997). Diagnostično-prognostična vloga norm nekaterih motoričnih sposobnosti pri mlajših otrocih. Maribor: Pedagoška fakulteta.

Strel, J., Mišič, G., \& Strel, J. (2016). Klinična pot. In Strel, J., Mišič, G., Strel, J. in Glažar, T. (Eds.), Telesna zmogljivost za boljše zdravje in počutje: vloga osnovnega zdravstva in lokalne skupnosti pri zagotavljanju ustrezne telesne zmogljivosti po vrhniškem modelu. Logatec: Fitlab.

Šimunič, B. (2008). Otrok med vplivi sodobnega življenjskega sloga - gibalne sposobnosti, telesne značilnosti in zdravstveni status Slovenskih otrok. Koper: Univerza na Primorskem, Znanstveno-raziskovalno središče Koper, Inštitut za kineziološke raziskave.

Šimunič, B., Volmut, T., \& Pišot, R. (2010). Otroci potrebujemo gibanje: otrok med vplivi sodobnega življenjskega sloga-gibalne sposobnosti, telesne značilnosti in zdravstveni status slovenskih otrok. Koper: Univerza na Primorskem. Znanstveno-raziskovalno središče. Inštitut za kineziološke raziskave. Založba Annales. 
Škof, B. (2016). Gibanje in gibalni razvoj. In Škof, B. in Bratina, N. (Eds.), Šport po meri otrok in mladostnikov - 2. dopolnjena izdaja. (str. 304-343). Ljubljana: Univerza v Ljubljani, Fakulteta za šport.

Tucker, P., \& Gilliland, J. (2007). The effect of season and weather on physical activity: a systematic review. Public health, 121(12), 909-922.

Videmšek, M., \& Pišot, R. (2007). Šport za najmlajše. Ljubljana: Fakulteta za šport.

Videmšek, M., \& Visinski, M. (2001). Športne dejavnosti predšolskih otrok. Ljubljana: Fakulteta za šport.

Volmut, T., \& Šimunič, B. (2016). Količina in intenzivnost gibalne/športne aktivnosti otrok v zgodnjem otroštvu. In Plevnik, M. in Pišot, R. (Eds.), Razvoj elementarnih gibalnih vzorcev v zgodnjem otroštvu. Koper: Univerzitetna založba Annales.

Zajec, J., Videmšek, M., Štihec, J., \& Šimunič, B. (2010). Odvisnost organiziranih športnih dejavnosti od materialnih, vsebinskih, organizacijskih in kadrovskih vidikov za izvajanje gibanja v vrtcu. . In Šimunič, B., Volmut, T., Pišot, R. (Eds.), Otroci potrebujemo gibanje: otrok med vplivi sodobnega življenjskega sloga - gibalne sposobnosti, telesne značilnosti in zdravstveni status slovenskih otrok. Koper: Univerza na Primorskem. Znanstveno-raziskovalno središče. Inštitut za kineziološke raziskave. Založba Annales.

Zdešar, T., \& Porenta, T. (2016) Predšolski otroci. In Strel, J., Mišič, G., Strel, J. in Glažar, T. (Eds.), Telesna zmogljivost za boljše zdravje in počutje: vloga osnovnega zdravstva in lokalne skupnosti pri zagotavljanju ustrezne telesne zmogljivosti po vrhniškem modelu. Logatec: Fitlab.

Zhou, Z., Ren, H., Yin, Z., Wang, L., \& Wang, K. (2014). A policy-driven multifaceted approach for early childhood physical fitness promotion: impacts on body composition and physical fitness in young Chinese children. BMC pediatrics, 14(1), 118.

Zurc, J. (2008). Biti najboljši: pomen gibalne aktivnosti za otrokov razvoj in šolsko uspešnost. Radovljica: Didakta.

Zurc, J. (2011). Gibalna aktivnost slovenskih otrok. Šport: Revija za teoretična in praktična vprašanja športa, 59, 126-131. 